\title{
Estimation of Corrosion-Free Life for Concrete Containing Ground Granulated Blast-Furnace Slag under a Chloride-Bearing Environment
}

\author{
Sung In Hong and Ki Yong Ann \\ Department of Civil and Environmental Engineering, Hanyang University, Ansan 15588, Republic of Korea \\ Correspondence should be addressed to Ki Yong Ann; kann@hanyang.ac.kr
}

Received 15 March 2017; Accepted 6 June 2017; Published 24 July 2017

Academic Editor: Xiao-Jian Gao

Copyright ( 2017 Sung In Hong and Ki Yong Ann. This is an open access article distributed under the Creative Commons Attribution License, which permits unrestricted use, distribution, and reproduction in any medium, provided the original work is properly cited.

\begin{abstract}
The rate of chloride transport by diffusion in concrete containing ground granulated blast-furnace slag (GGBS) was mathematically estimated to predict the corrosion-free service life of concrete structures exposed to seawater environment. As a factor to corrosiveness of steel embedment, replacement ratio of GGBS was selected, accounting for 25 and $50 \%$ to total binder. As a result, it was found that an increase in the GGBS content resulted in an increase in the chloride binding capacity, which would give rise to a lower chloride diffusion rate, thereby reducing the risk of chloride-induced corrosion. When it comes to the sensitivity of parameters to service life, the effective diffusivity showed a marginal influence on serviceability, irrespective of GGBS contents while surface chloride content and critical threshold concentration revealed more crucial factors to long term chloride diffusion. As the GGBS replacement increased, the variation in service life has become less influential with changing parameters. Substantially, GGBS concrete at high replacement ratio enhanced the service life due to a combination of dense pore structure and enhanced chloride binding capacity.
\end{abstract}

\section{Introduction}

Steel corrosion in concrete mainly occurs by dissolution of passive film (i.e., thin layer of iron oxide) which is formed in the high alkaline pore solution and can protect the steel from corrosion [1]. When a certain amount of chloride ions reaches the steel embedment, pit nucleation on the steel surface accompanies a $\mathrm{pH}$ drop in the concrete pore solution to initiate the corrosion process [2]. Then, volume expansion of corrosion products induces cracking of cover concrete, together with a reduction of steel area, leading to structural failure.

To mitigate the corrosion process in terms of chloride transport and corrosiveness, lots of attention has been drawn to development of durable concrete using supplementary cements such as GGBS, silica fume, and fly ash. Among them, GGBS concrete is known to be durable material in terms of dense pore structure and chemically improved resistance to chloride penetration. GGBS has high alumina content typically within $8-18 \%$ [3], compared with OPC which enables binding chloride ions penetrating into concrete at much higher level. Though the initial development of strength is generally weaker, the effect of latent hydration promotes durability of the material after enough curing period. This is especially dominant in using high replacement ratio, about $55-60 \%$ by binder mass [4]. Moreover, efficiencies to reduce cost for Portland cement usage and generation of $\mathrm{CO}_{2}$ from the cement production [4] are also valid in using GGBS concrete.

Despite these potential feasibilities in GGBS concrete, serviceability assessment for GGBS concrete as to long term chloride attack has been rarely conducted. For example, dealing with chloride diffusion in GGBS concrete for 30 years of chloride exposure shows substantial reduction of chloride diffusivity with time [5]. Though time dependent chloride diffusivity was considered, the effect of chloride binding capacity on the rate of chloride diffusion was not reflected in this analysis. This might give rise to unrealistic chloride profile which would otherwise lead to the concentration dependent rate of diffusion if chloride binding capacity is considered [6-8]. 
This study concerns chloride diffusion in GGBS concrete depending on its replacement ratio where chloride binding capacity and chloride diffusivity are affected. Determination of chloride binding capacity was achieved by the Freundlich isotherm with experimentally obtained data to represent the nonlinear relation of chloride phases during diffusion process. Additionally, the rate of chloride adsorption was considered based on mass transfer theory [9], representing nonequilibrium state of chloride phase transition, in terms of resistance to chloride binding. Accordingly, the concentration dependent chloride binding capacity and chloride diffusivity were achieved and then chloride diffusion at nonsteady state was determined to predict chloride diffusion in GGBS concrete.

\section{Transient Diffusion Model}

To evaluate durability of GGBS concrete against chlorideinduced corrosion, chloride diffusion under nonsteady state was modeled. As for the chloride phases in concrete, this paper considers free chloride, defined as a mobile phase in pore solution, bound chloride defined as immobilized phase adsorbed in hydrates, and total chloride for the sum of the free and bound chlorides. The free chloride is only one phase that diffuses through concrete media under continuous adsorption process. For the mixes, GGBS based blended cements, of which replacement ratios are 0,25 , and $50 \%$ by total binder mass with 0.5 of water-to-binder ratio $(\mathrm{W} / \mathrm{B})$, were maintained.

2.1. Governing Equation. In this study, chloride diffusion was considered as a main driving force through concrete media, assuming that the electrical interruption with other ionic species and moisture gradient are absent in concrete pore system. Hence, chloride transport in concrete submerged in a saline environment can be described as a one-dimensional transient diffusion such that

$$
\frac{d C_{f}}{d t}=D_{a}\left(C_{f}\right) \frac{d^{2} C_{f}}{d x^{2}},
$$

where $C_{f}$ is the free chloride concentration (percentage by binder mass), $t$ is the time (sec), $x$ is the penetration distance $(\mathrm{m})$, and $D_{a}$ is the apparent diffusion coefficient $\left(\mathrm{m}^{2} / \mathrm{s}\right)$. The apparent diffusivity, incorporating effects of pore structure and chloride binding on the rate of chloride penetration, can be written as

$$
D_{a}=\frac{D_{e}}{1+d C_{b} / d C_{f}},
$$

where $D_{e}$ is the effective diffusion coefficient $\left(\mathrm{m}^{2} / \mathrm{s}\right)$ and $C_{b}$ is the bound chloride concentration (percentage by binder mass). The derivative term, $d C_{b} / d C_{f}$, in (2) corresponds to the binding capacity [7] which in turn leads to the concentration dependent diffusivity.

2.2. Chloride Binding. Distribution of chlorides in concrete during the diffusion process is continuously affected by chloride reaction with hydrates. As for nonlinear relation between free and bound chlorides, the present study adopted
Freundlich isotherm, describing equilibrium state of chlorides in concrete such that

$$
C_{b}=\alpha\left(C_{f}^{*}\right)^{\beta}
$$

where $\alpha$ and $\beta$ are the regression parameters from Freundlich isotherm and $C_{f}^{*}$ is the free chloride concentration at interface between pore solution and solid surface (percentage by binder mass). To consider the concentration dependent rate of chloride adsorption, transition of $C_{f}$ in relatively unstable pore solution (i.e., agitated solvent) into $C_{f}^{*}$ in relatively stable state of pore solution directly contacted with the surface of hydrate was described using the mass transfer theory [9]. Accordingly, the amount of adsorbed chlorides at given unit time can be expressed as

$$
\frac{d C_{b}}{d t}=k\left(C_{f}-C_{f}^{*}\right)
$$

where $k$ is the overall mass transfer coefficient $(1 / s)$ that specifies velocity of mass transfer from bulk pore solution into adsorption site of hydrates. When the $C_{f}$ is relatively smaller than that of interface (i.e., $C_{f}^{*}$ ), the desorption process occurs in the system.

2.3. Mathematical Treatment. To predict the chloride diffusion in concrete in the presence of chloride binding, the governing equation described in (1) was modified using (2)-(4) such that

$$
\frac{d C_{f}}{d t}+k\left(C_{f}-\left(\frac{C_{b}}{\alpha}\right)^{\beta^{-1}}\right)=D_{e} \frac{d^{2} C_{f}}{d x^{2}} .
$$

Due to nonlinearity in partial differential form (i.e., (5)), explicit finite difference method with $0.001 \mathrm{~m}$ and 1.0 day as the step sizes of distance and time, respectively, was used to solve it. The derivative terms for time and distance were expressed as forward difference and central difference, respectively. Then, those chloride concentrations (i.e., $C_{f}$ and $C_{b}$ ) were calculated by applying the mass balance equation to (5) such that

$$
\frac{d C_{t}}{d t}=\frac{d C_{f}}{d t}+\frac{d C_{b}}{d t}=D_{e} \frac{d^{2} C_{f}}{d x^{2}},
$$

where $C_{t}$ is the total chloride (percentage by binder mass). Iterative procedure was carried out on (5) and (6) until relative change of solutions in a unit time increment is achieved below $10^{-6}$. As for the boundary condition, the external chloride concentration submitted to the concrete surface was set by $0.5 \mathrm{M}$ of sodium chloride, aiming to mimic that of seawater together with initially zero concentration in concrete. Thus, it is possible to implement numerical solutions for free, bound, and total chloride concentrations along the concrete depth with time.

2.4. Determination of Input Parameters. For chloride diffusion analysis using concrete mixes varying with GGBS replacements, an experimental work for chloride binding test was conducted. Fabrication of samples was carried out on 
TABLE 1: Parameter values of pore structure.

\begin{tabular}{lcc}
\hline Binder type & Water filled porosity $(\mathrm{ml} / \mathrm{g})$ & $\begin{array}{c}\text { Effective diffusivity } \\
\left(E-12 \mathrm{~m}^{2} / \mathrm{s}\right)[12]\end{array}$ \\
\hline OPC & 0.26 & 1.82 \\
$25 \%$ GGBS & 0.34 & 1.39 \\
$50 \%$ GGBS & 0.31 & 1.01 \\
\hline
\end{tabular}

cement paste with $0.5 \mathrm{~W} / \mathrm{B}$ in which nine levels of sodium chloride content $(0.1-3.0 \%$ by cement) were initially mixed. Then, water curing under $20 \pm 1^{\circ} \mathrm{C}$ was taken on all the samples for 56 days. After that, about $5 \mathrm{~g}$ of powder was collected from fragments of cement pastes and was mixed with water at $50^{\circ} \mathrm{C}$, followed by stirring about $30 \mathrm{~min}$ until equilibrium state is reached in the solution. Then, the concentration of chloride in solution, filtered with filtering paper, was measured by potentiometric titration against silver nitrate. Thus, free chloride concentrations were determined directly by this procedure and thus bound chloride concentrations were obtained by subtracting free one from initial total chloride content. Hence, it is possible to obtain binding isotherm constants, $\alpha$ and $\beta$, by regression analysis using Freundlich model (3). As for the mass transfer coefficient, $k$, it was set by $7.58 \times 10^{-7} \mathrm{~s}^{-1}$ for all the cases due to marginal difference observed within the values from related analysis $[10,11]$.

To determine the surface chloride content, mercury intrusion porosimetry was carried out on mortar samples with OPC, $25 \%$ and 50\% GGBS. The samples for the test were made by adjusting a mix proportion as $0.5 \mathrm{~W} / \mathrm{B}$ and 2.12 of sand-to-binder ratio. After water immersion for 56 days, fragments from the samples were obtained and dried in oven to evacuate most of pore solution inside the materials. At constant contact angle $\left(130^{\circ}\right)$ for mercury intrusion and extrusion, the pressure from the device was gradually increased up to maximum pressure $(228 \mathrm{MPa})$. After the test, total intrusion of mercury for given samples was obtained. Then, using the values and information of unit binder mass, it is possible to obtain water filled porosity, defined by volume of pore solution per mass of binder. Those parameters including literature values of effective diffusivity for GGBS concrete [12] which are comparable with mixtures considered in this study are given in Table 1. As increasing the GGBS contents, the values of effective diffusivity were reduced due to denser pore structure while the values of water filled porosity appear to be inconsistent with the replacement ratio. This might be due to lower density of GGBS mortar at same unit mass of binder applied as compared with OPC mortar. Moreover, the latent hydration in GGBS gives rise to lower connectivity of pore network for effective diffusion path [13], which is more dominant in the case of higher GGBS replacement.

\section{Result and Discussion}

3.1. Effect of Chloride Binding on Diffusion Behavior. GGBS concrete has relatively higher amount of $\mathrm{C}_{3} \mathrm{~A}$ content, imposing the increased binding capacity [19]. For determining binding capacity with GGBS replacement ratios, the relation of free and bound chlorides was experimentally obtained

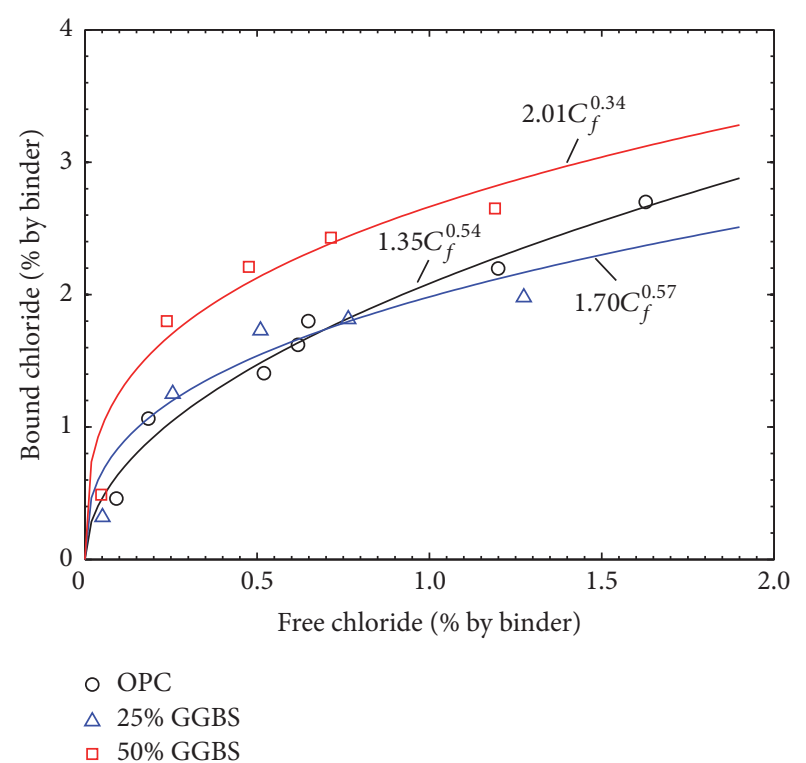

FIGURE 1: Regression plots of Freundlich isotherm with experimental data.

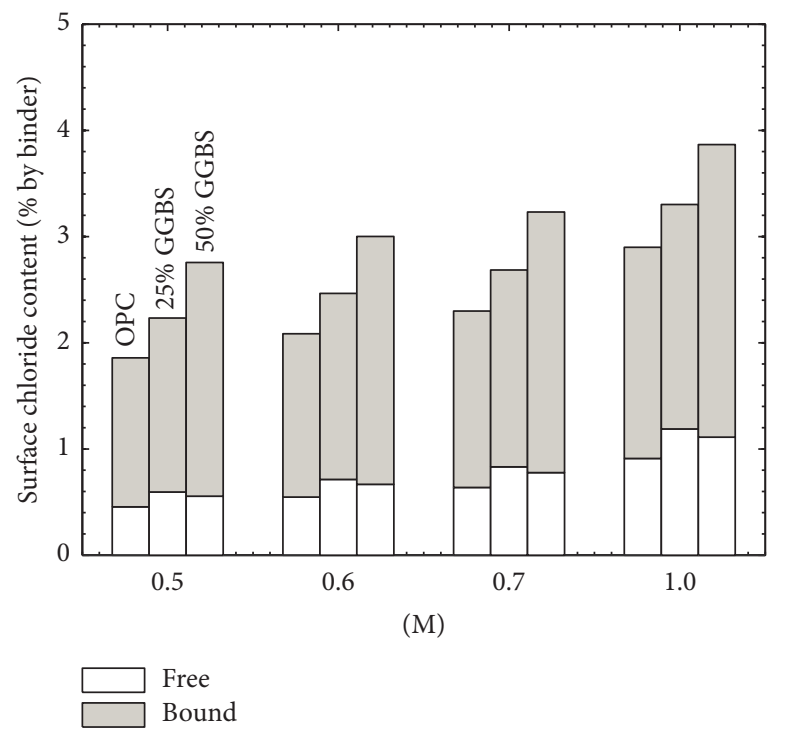

FIGURE 2: Surface chloride contents with variation of external chloride concentration.

using the Freundlich relation. As shown in Figure 1, the Freundlich isotherm was reasonably fitted by the data in all the range of concentrations. As replacement ratio increases, the relative amount of bound chloride at a given free one was increased. Accordingly, 50\% GGBS indicated the highest binding capacity, followed by 25\% GGBS while OPC showed the lowest one. However, at about $0.8 \%$ free chloride content over that of the external solution (i.e., $0.5 \mathrm{M}$ of chloride ion), the crossover in binding capacity between OPC and 25\% GGBS was observed. To evaluate the effect of binding capacity on chloride concentration at surface, external reservoirs for chloride source up to $1.0 \mathrm{M}$ were used to derive the corresponding free, bound, and total chlorides. As shown in Figure 2, total chlorides were gradually increased with 


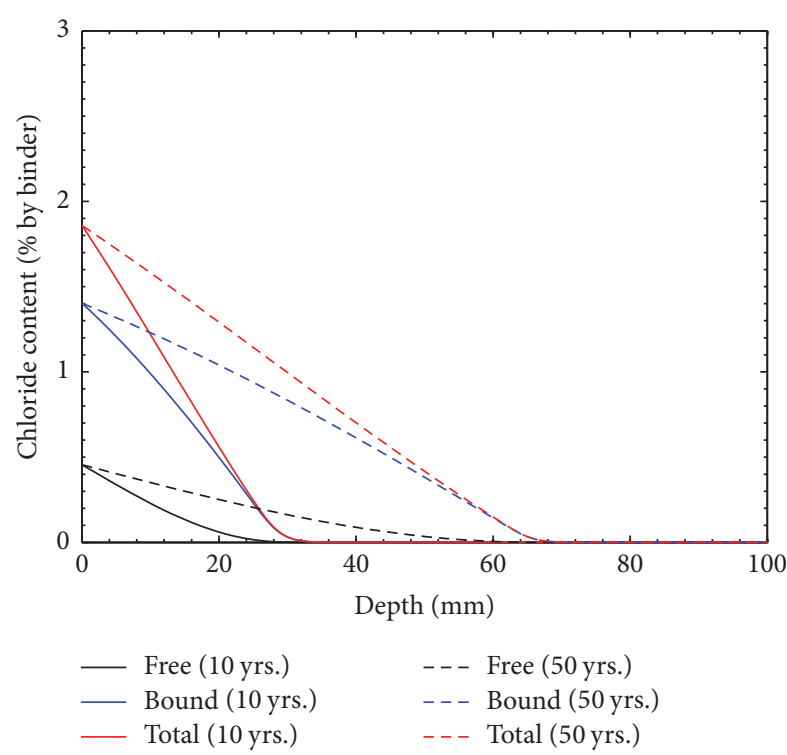

(a) OPC

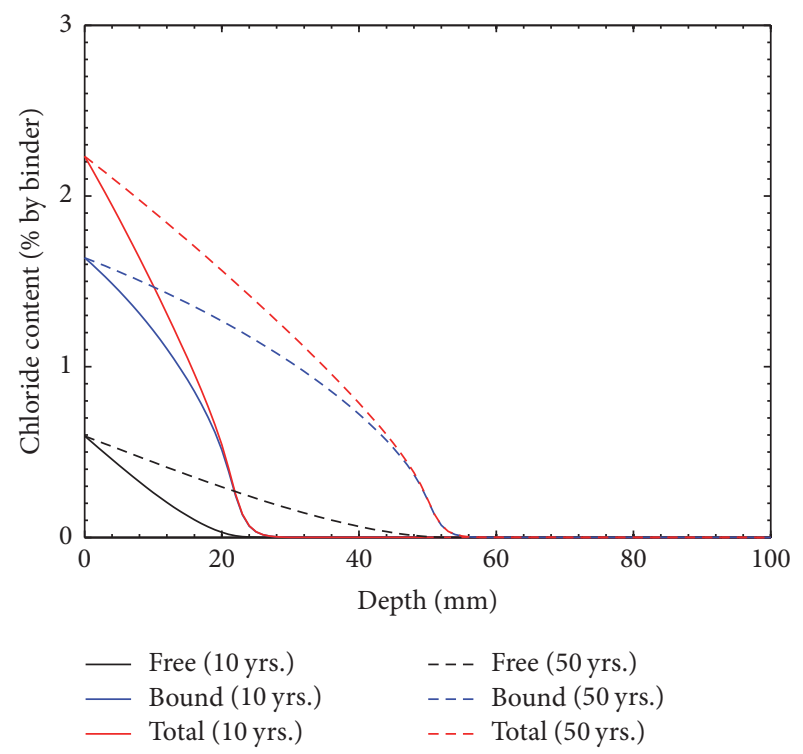

(b) $25 \%$ GGBS

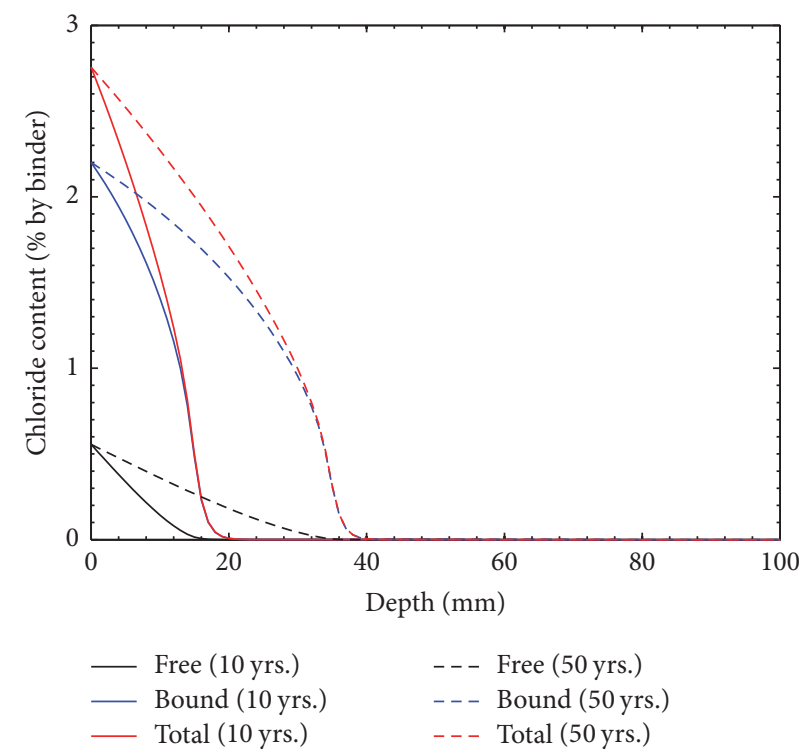

(c) $50 \%$ GGBS

FIgURE 3: Prediction of concentrations for free, bound, and total chlorides at 10 and 50 years.

the concentration of external solution while free chlorides showed a proportional increase to the external concentration. Despite the low free chloride, 50\% GGBS showed the highest total chloride content, irrespective of external concentrations. In case of OPC, total chloride was lowest at all the concentration range. This reveals that the binding capacity would be a more deterministic factor to the surface chloride content rather than open porosity. Hence, the chloride diffusion might be affected as concentration gradient is enhanced by the higher surface chloride content arising from chloride binding.

To assess the effect of chloride binding on the diffusion front, 10 and 50 years of chloride penetration were simulated, as given in Figure 3. It is seen that the shape of total chloride profile for OPC differs between 25\% and 50\% GGBS while those for free chloride are similar to each other, irrespective of time. Higher binding capacity at lower concentration is much dominant in case of GGBS, as indicated by Figure 1. This leads to sharp decrease in total chloride near the maximum penetration depth; see Figures 3(b) and 3(c). Thus, relatively even chloride distribution can be achieved in OPC due to smaller change in binding capacity with chloride concentration, as shown in Figure 3(a). The surface chloride content accounts for $1.86,2.23$, and 2.75 in percentage of binder mass for OPC, 25\% and 50\% GGBS, respectively. These concentrations are constant with time in the assumption of instantaneous chlorides equilibrium condition between salt solution and concrete surface. This implies that in long term 


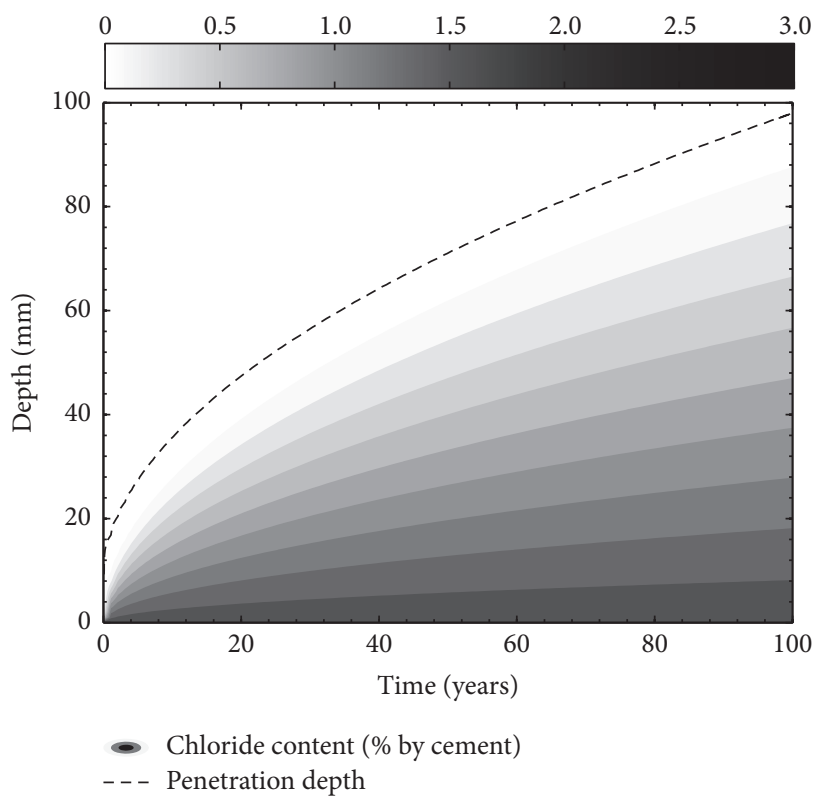

(a) OPC

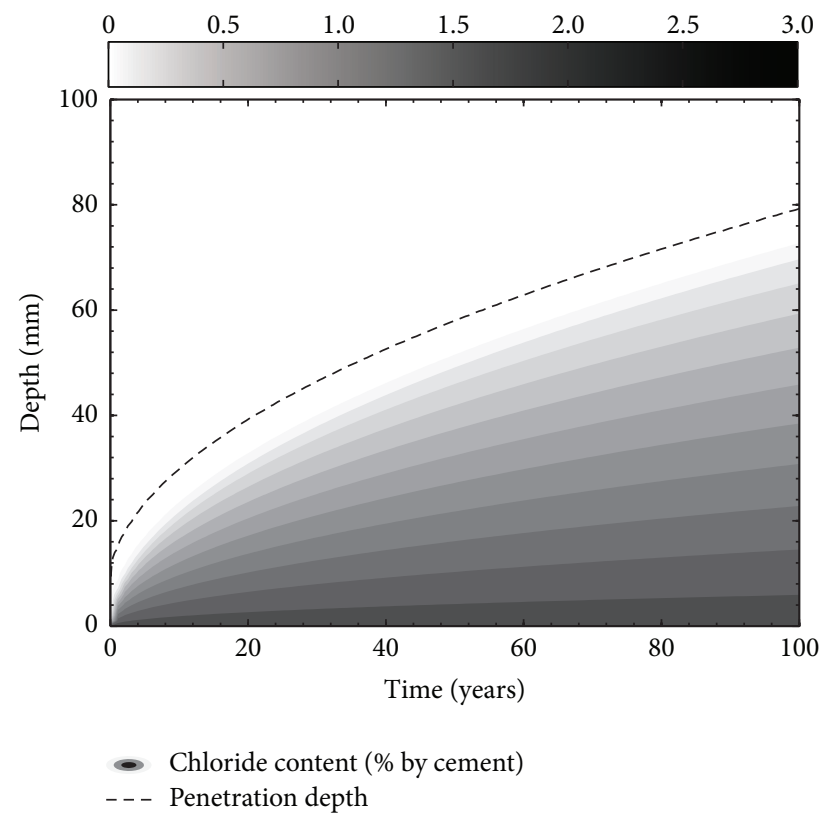

(b) $25 \%$ GGBS

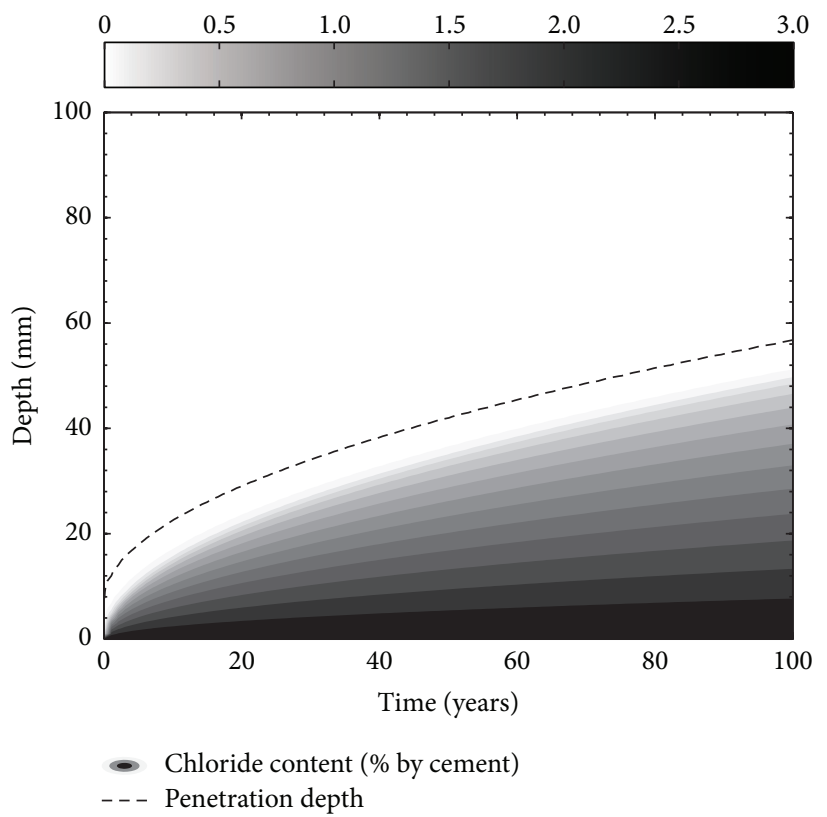

(c) $50 \%$ GGBS

FIGURE 4: Contour plots of total chloride contents with variation of depth and time.

chloride exposure, sudden increase in chloride accumulation at steel depth could be imposed in case of GGBS due to relatively large amount of total chloride supplied from higher surface chloride content.

3.2. Rate of Chloride Diffusion. Chloride distribution in concrete with a sequent exposure for 100 years was calculated to determine the chloride diffusion in GGBS concrete, as given in Figure 4. Values on each contour color correspond to equal concentration range and dash lines denote the maximum penetration depth, defined by a location where concentration starts to drop below $10^{-3} \%$ by binder mass. The chloride concentrations along the concrete depth are dependent on time of exposure, indicating initially higher rate of penetration, defined herein as the ratio of maximum penetration depth to the corresponding exposure time, followed by gradual trend. The rate of increment in maximum penetration depth over 100 years accounted for approximately $0.81,0.64$, and $0.45 \mathrm{~mm} /$ year for OPC, $25 \%$ and $50 \%$ GGBS, respectively. For OPC, the rate of chloride penetration was mostly higher with all the exposure time, leading to the linearly distributed concentration along depth, as seen in 
TABLE 2: Chloride threshold values from literatures with variation of GGBS replacement.

\begin{tabular}{|c|c|c|c|c|c|}
\hline CTL, $\%$ by binder & Replacement, \% by binder & Water-to-binder ratio & Chloride source & Corrosion detection & Reference \\
\hline $0.5-1.0$ & 0 & $0.5-0.7$ & Internal & Macrocell current & {$[14]$} \\
\hline $0.78-0.93$ & - & $0.35-0.55$ & - & Half-cell potential & {$[15]$} \\
\hline $0.74-0.93$ & - & 0.4 & - & Polarisation & {$[2]$} \\
\hline $0.47-1.52$ & - & 0.45 & External & Galvanic current & {$[16]$} \\
\hline 0.97 & 30 & 0.45 & Internal & Half-cell potential & {$[15]$} \\
\hline $1.0-1.5$ & 50 & $0.5-0.6$ & Internal & Macrocell current & {$[14]$} \\
\hline $0.4-0.9$ & - & 0.4 & External & Polarisation, galvanostatic pulse & {$[17]$} \\
\hline $0.29-0.44$ & 60 & 0.4 & Internal & Polarisation & {$[2]$} \\
\hline $0.53-0.80$ & 65 & 0.4 & External & Galvanic current & {$[16]$} \\
\hline $0.82-1.14$ & 70 & 0.48 & External & Half-cell potential & {$[18]$} \\
\hline
\end{tabular}

Figure 4(a). This might contribute to the relatively higher chloride diffusivity where chloride binding is less significant and then to enhancing the rate of chloride diffusion. As GGBS replacement ratio increased, the rate of chloride penetration significantly decreased, despite the higher concentration at surface of the media. In particular, for 50\% GGBS, all the chloride concentrations below $50 \mathrm{~mm}$ of concrete depth over 100 years were smaller than $0.4 \%$. This implies that concrete made with high portion of GGBS would be highly recommended in applying to a chloride laden environment if the possibility of releasing bound chloride is marginal. This might adversely induce the risk of corrosion if a $\mathrm{pH}$ reduction accompanying carbonation or acid attack is involved in the same environment [3].

To assess the concentration dependent characteristics on the rate of chloride ingress, the binding capacity along penetration distance was calculated from the concentration profile. As shown in Figure 5, it is seen that convergence of binding capacity started from the near maximum penetration depth since a change in the chloride concentration over the region was negligible. Also, increasing replacement ratio and exposure time led to increasing the chloride binding capacity along the penetration depth. As indicated in Figure 1, this relates to the concentration dependent binding capacity, of which the relative amount of bound chloride decreased with increasing free chloride content. Accordingly, a large portion of lower chloride content increased with chloride exposure time and simultaneously imposed the higher binding capacity within the depth. This consequently leads to a reduction in the rate of chloride penetration with time, as given in (2). Also, the nonsteady state condition where the rate of chloride diffusion is largely dependent on the chloride binding became nearly steady state in the chloride diffusion. After long period of the exposure, the equilibrium condition in concrete with concentrations of chlorides becomes preferably achieved near the external chloride source, as seen in the cases of 50 years in Figure 5, and simultaneously the variation of diffusion flux through the concrete depth gradually decreases. Hence, at that time the effective diffusivity became a more crucial factor to chloride transport.

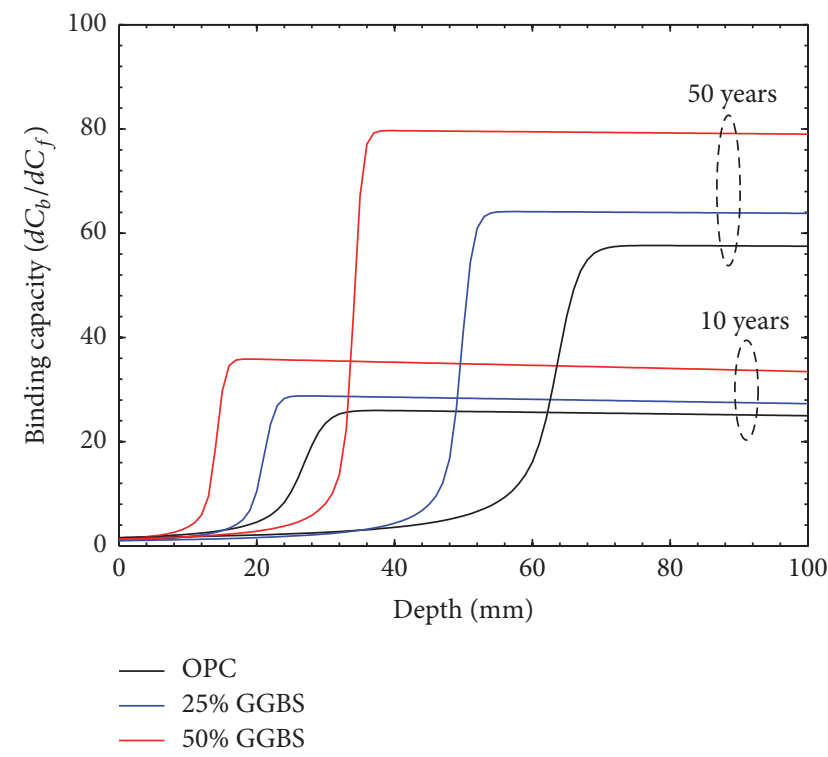

FIGURE 5: Distribution of binding capacity along chloride penetration with time.

3.3. Sensitivity Analysis of Chloride Diffusion. To evaluate serviceability of GGBS concrete in terms of chloride-induced corrosion, the chloride threshold level (CTL) was collected from literature data $[2,14-18]$. As shown in Table 2, no distinct relation was observed in CTL with GGBS replacement ratio. The irregular data might be attributed to (1) different mix condition and curing regime (2) different method for determination of CTL. Thus, for practical purpose, it was assumed that CTL was defined as $0.79 \%$ of total chloride by binder mass in the present study; the value was obtained from the average from all the data in literature review.

Sensitivity analysis to service life was carried out on the mixes with the rate parametric value of chloride transport $\left(C_{s}\right.$ and $\left.D_{e}\right)$ and CTL, as shown in Figures 6 and 7. The service life was defined by the chloride exposure period at which total chloride content begins to exceed CTL at the 


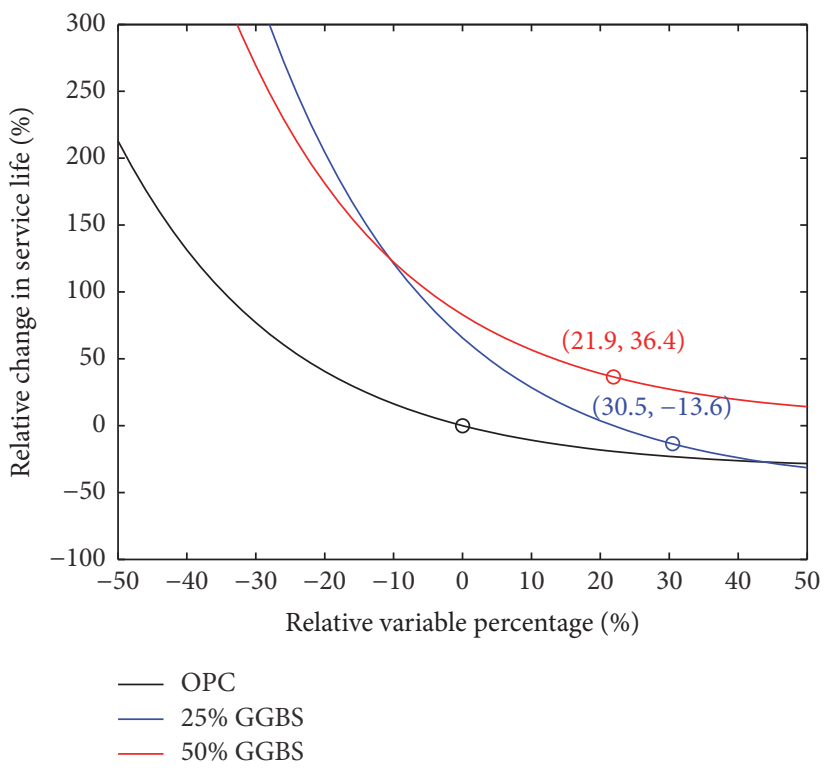

(a) Free $C_{s}$

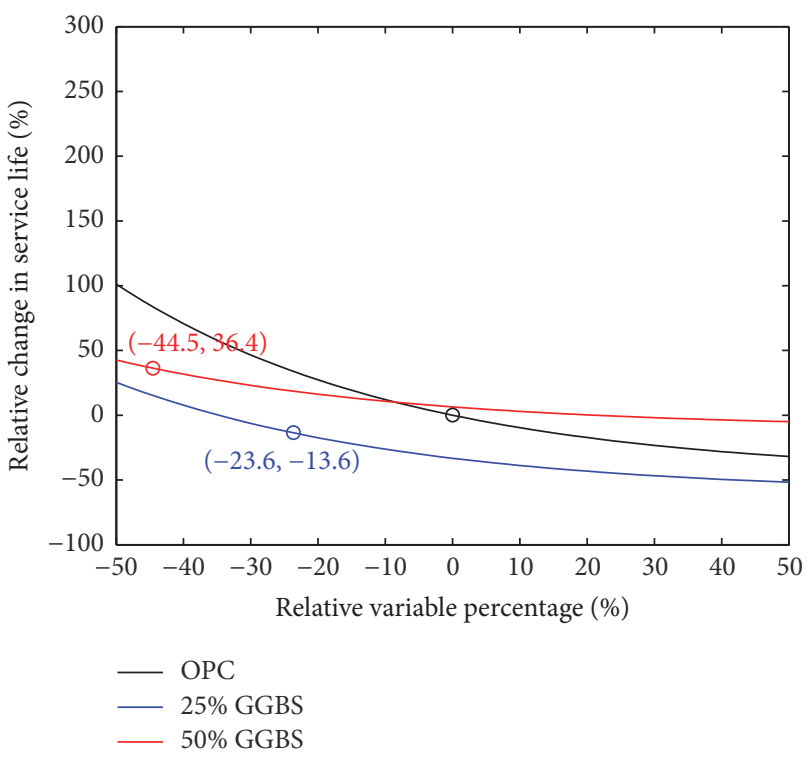

(b) $D_{e}$

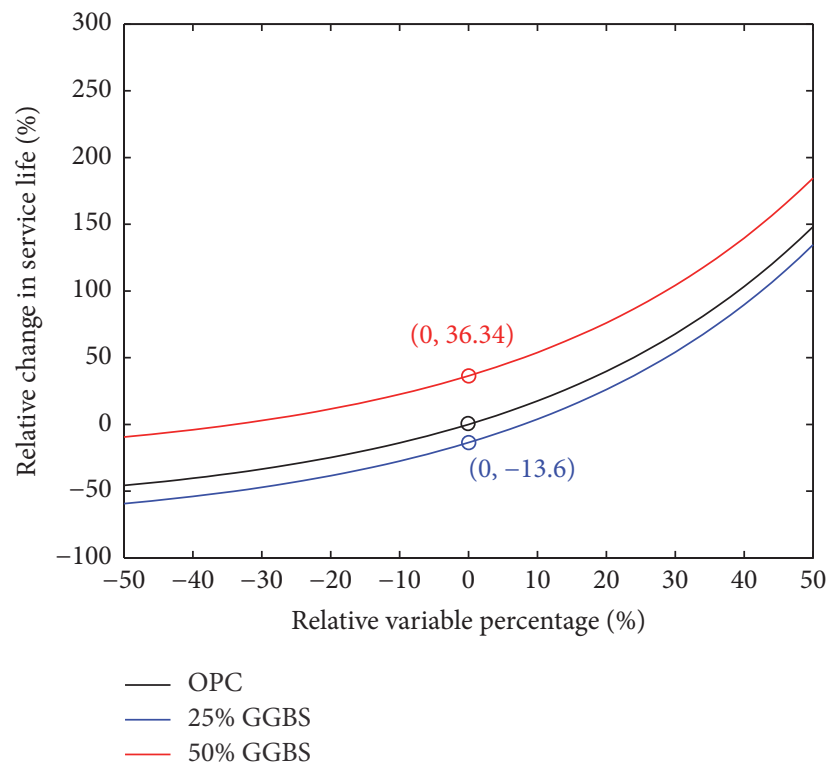

(c) CTL

FIGURE 6: Sensitivity of parameters to service life estimation with percentage change of variables.

steel depth, assumed to be $25 \mathrm{~mm}$ which is the minimum cover depth according to BS 8110 [20]. The relative variation of parameters for OPC and its influence on the corrosionfree life in terms of service life were calculated as given in Figure 6. It is evident that reducing $C_{s}$ and increasing CTL are highly beneficial in all the materials while influence of $D_{e}$ on serviceability is relatively low. It may arise from the variation range of $D_{e}$, which is usually in the range of one order of magnitude depending on concrete mix proportion including binder type and a free water binder ratio [21]. Thus the margin of $40 \%$ to the original value may have a marginal influence on the service life. However, $C_{s}$ is crucial to the onset of corrosion, as it imposes a build-up of chlorides on the concrete surface, which subsequently leads the driving force of chloride transport in terms of diffusivity in concrete. Moreover, the CTL would be more promising to secure the service life. For concrete exposed to a saline environment such as seawater, the maximum chloride concentration in concrete cannot exceed $2.0 \%$ by weight of cement, which in turn accounts for $0.8-1.0 \%$ for free chloride ions. Thus, at the depth of the steel, the concentration of chloride would be more or less in the range of $0.5-1.0 \%$. It implies that a margin for the CTL would be more sensitive to the corrosiveness or inhibition. Substantially, an increase in the CTL and a 


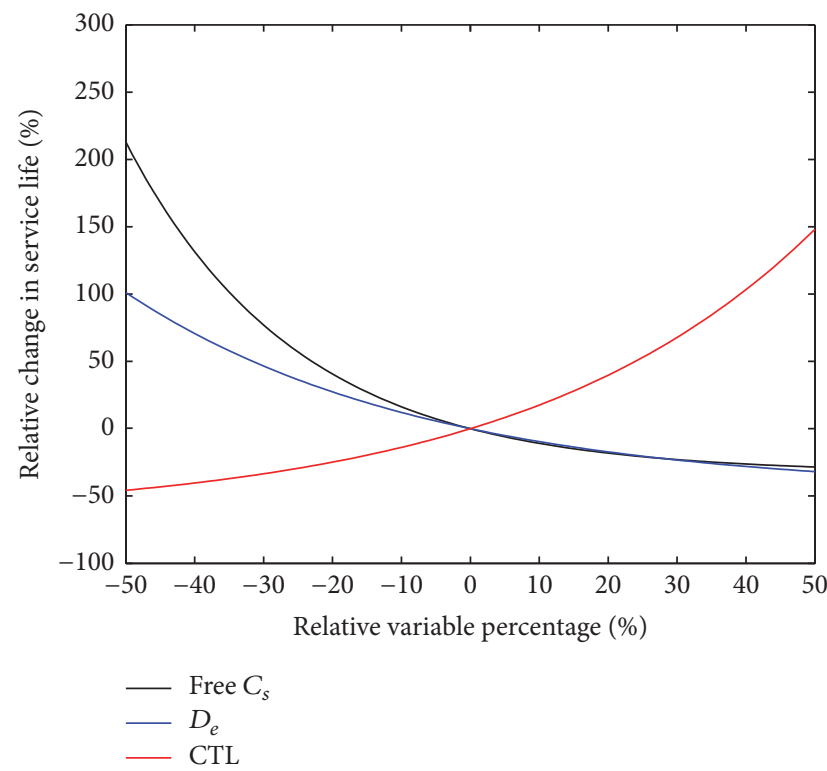

(a) OPC

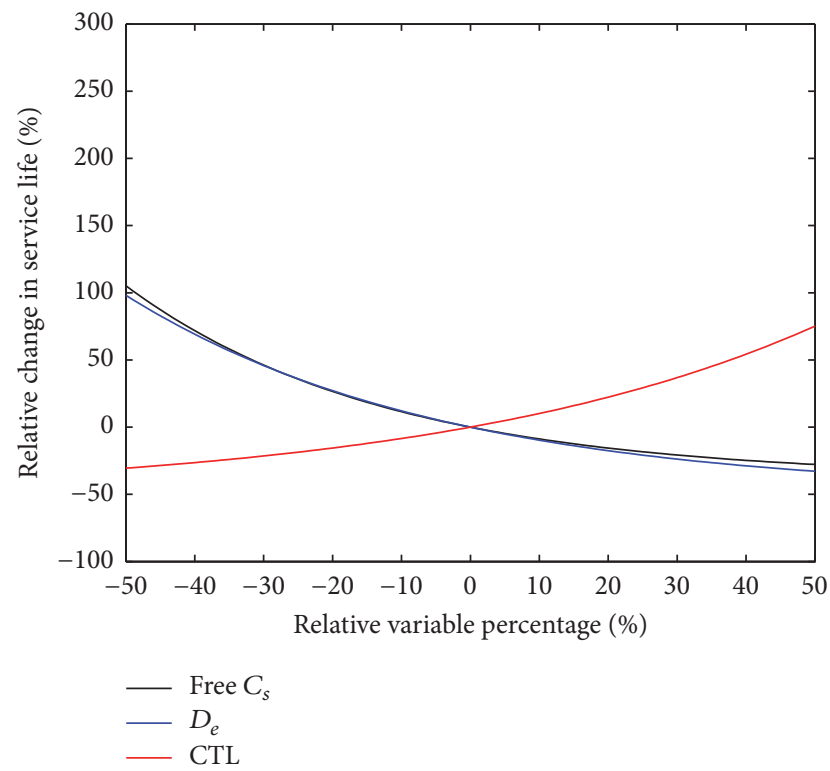

(b) $25 \%$ GGBS

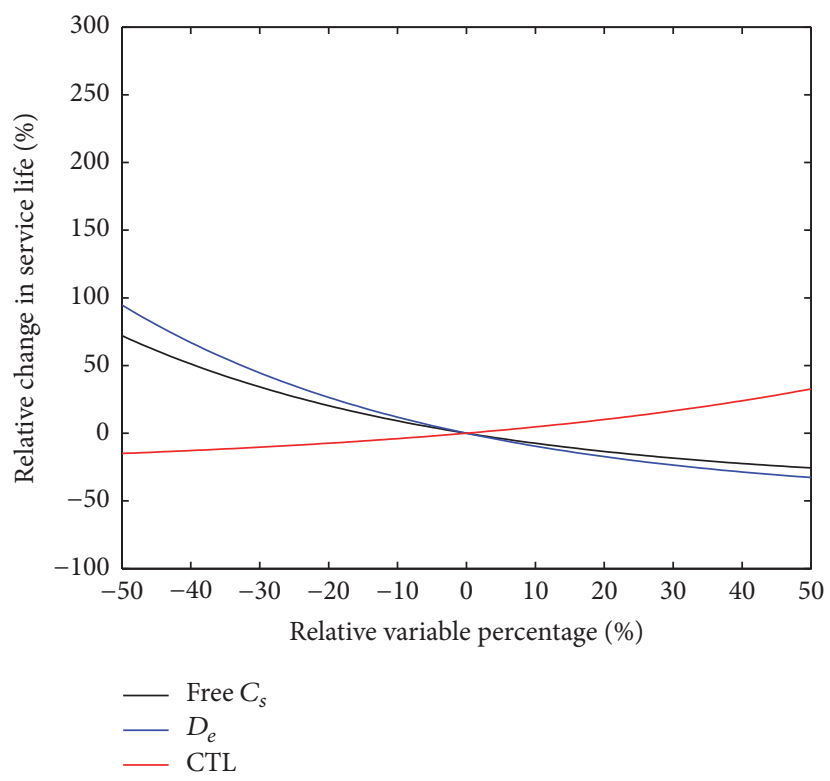

(c) $50 \%$ GGBS

FIGURE 7: Sensitivity of GGBS replacement ratio to service life estimation with percentage change of variables.

decrease in the $D_{e}$ must be accompanied to enhance the time to corrosion initiation, rather than rate of chloride transport, within a marginal range about $50 \%$ in the variation.

The dependence of service life on parametric values was calculated by the sensitivity of mix design in terms of binder type, as seen in Figure 7 . The sensitivity of parameters to service life is predominant in OPC and becomes smaller with increasing replacement ratio, probably due to higher binding capacity that is much influential in chloride diffusion than those parameters. Therefore, it is inferred that chemically improved materials as to (1) using cement with high portion of alumina content to increase chloride binding capacity,
(2) surface treatment to reduce $C_{s}$ [22], and (3) using corrosion inhibitors to increase CTL [23] are recommended to enhance the resistance to chloride-induced corrosion. In fact, a replacement of GGBS in concrete would alternatively achieve at a lower water-to-binder ratio these barrier effects; increased binding capacity and dense pore structure would sustain the steel embedment passive in a long term. However, the resistance of GGBS concrete to chloride-induced corrosion may be adversely lowered, compared to OPC ones. This was experimentally investigated using $65 \%$ GGBS of which lower buffering capacity was measured [24] where in turn rate of corrosion may be accelerated by lowered $\mathrm{pH}$ in pore solution in the vicinity of steel. This also could result in a risk 
for bound chloride to participate in steel corrosion process. However, as indicated by Figure 4, chloride transport resistivity using high replacement ratio of GGBS is always dominant in all periods of exposure, compared to OPC. This is also indicated by Figure 7 where relative variation of service life by reducing CTL is less significant in using GGBS. Accordingly, despite lower ability of acid neutralization against chloride ion in steel surface, concrete made with high portion of GGBS cement is quite suitable for application in marine structure.

\section{Conclusion}

The present study aims to assess the long term chloride diffusion in concrete in consideration of GGBS replacement ratio. As a key factor to chloride diffusion, a nonlinear chloride binding isotherm, dependent on mix proportion, was used to describe the chloride diffusion behavior with time. From the result, the conclusion was obtained as follows.

(1) GGBS replacement leads to proportionally increased chloride binding capacity which in turn increases the surface chloride concentration at given chloride source. Moreover, the shape of chloride front was shown to be largely affected by concentration dependent binding isotherm where small concentration near the maximum penetration depth imposes a sharp drop in total chloride content.

(2) Simulation for 100 years of exposure to saline water was shown where the rate of chloride penetration was predominant by the effective diffusivity and chloride binding capacity. Accordingly, OPC concrete showed highest rate of chloride transport in terms of diffusivity, compared to GGBS at all the exposure period. From the distribution of chloride binding capacity along the penetration depth, time dependent rate of chloride diffusion was observed where high portion of GGBS content shows large reduction in apparent diffusivity.

(3) Sensitivity analysis of parameters for the service life estimation revealed that relatively lower variation of service life was observed in case of effective diffusivity while the surface chloride content and CTL were more crucial factors to the chloride diffusion. Furthermore, increased portion of GGBS showed lower risk of chloride-induced corrosion with variation of parameters. This implies that due to higher binding capacity and lower chloride diffusivity, GGBS concrete may be beneficial in a chloride laden environment despite its low resistivity to corrosion at steel surface.

\section{Conflicts of Interest}

The authors declare that they have no conflicts of interest.

\section{Acknowledgments}

This research was supported by Technology Advancement Research Program funded by Ministry of Land, Infrastructure and Transport of Korean Government (Grant 15CTAPC097546-01).

\section{References}

[1] C. L. Page, "Mechanism of corrosion protection in reinforced concrete marine structures," Nature, vol. 258, pp. 514-515, 1975.

[2] H.-W. Song, M.-S. Jung, C.-H. Lee, S.-H. Kim, and K. Y. Ann, "Influence of chemistry of chloride ions in cement matrix on corrosion of steel," ACI Materials Journal, vol. 107, no. 4, 2010.

[3] A. M. Neville, Properties of Concrete, Longman Group, London, 4th edition, 1995.

[4] A. Oner and S. Akyuz, "An experimental study on optimum usage of GGBS for the compressive strength of concrete," Cement and Concrete Composites, vol. 29, no. 6, pp. 505-514, 2007.

[5] M. D. A. Thomas and P. B. Bamforth, "Modelling chloride diffusion in concrete: effect of fly ash and slag," Cement and Concrete Research, vol. 29, no. 4, pp. 487-495, 1999.

[6] G. Sergi, S. W. Yu, and C. L. Page, "Diffusion of chloride and hydroxyl ions in cementitious materials exposed to a saline environment," Magazine of Concrete Research, vol. 44, no. 158, pp. 63-69, 1992.

[7] B. Martín-Pérez, H. Zibara, R. D. Hooton, and M. D. A. Thomas, "Study of the effect of chloride binding on service life predictions," Cement and Concrete Research, vol. 30, no. 8, pp. 12151223, 2000.

[8] G. K. Glass and N. R. Buenfeld, "The influence of chloride binding on the chloride induced corrosion risk in reinforced concrete," Corrosion Science, vol. 42, no. 2, pp. 329-344, 2000.

[9] C. N. Satterfield and T. K. Sherwood, "The Role of Diffusion in Catalysis," Wesley series in chemical engineering, AddisonWesley, Massachussets, Mass, USA, 1963.

[10] P. J. Tumidajski, "Application of Danckwerts' solution to simultaneous diffusion and chemical reaction in concrete," Cement and Concrete Research, vol. 26, no. 5, pp. 697-700, 1996.

[11] P. Spiesz, M. M. Ballari, and H. J. H. Brouwers, "RCM: a new model accounting for the non-linear chloride binding isotherm and the non-equilibrium conditions between the freeand bound-chloride concentrations," Construction and Building Materials, vol. 27, no. 1, pp. 293-304, 2012.

[12] K. Y. Yeau and E. K. Kim, "An experimental study on corrosion resistance of concrete with ground granulate blast-furnace slag," Cement and Concrete Research, vol. 35, no. 7, pp. 1391-1399, 2005.

[13] S.-W. Pack, M.-S. Jung, H.-W. Song, S.-H. Kim, and K. Y. Ann, "Prediction of time dependent chloride transport in concrete structures exposed to a marine environment," Cement and Concrete Research, vol. 40, no. 2, pp. 302-312, 2010.

[14] P. Schiebl and M. Raupach, "Durability of local repair measures on concrete structures damaged by reinforcement corrosion," Special Publication, vol. 145, pp. 1195-1216, 1994.

[15] B. H. Oh, S. Y. Jang, and Y. S. Shin, "Experimental investigation of the threshold chloride concentration for corrosion initiation in reinforced concrete structures," Magazine of Concrete Research, vol. 55, no. 2, pp. 117-124, 2003.

[16] K. Y. Ann, Enhancing the Chloride Threshold Level for Steel Corrosion in Concrete [Ph.D. thesis], University of London, London, UK, 2005. 
[17] P. Sandberg, "Chloride initiated reinforcement corrosion in marine concrete," Report TVBM 1015, 1998.

[18] P. B. Bamforth, "Derivation of input data for modelling chloride ingress from eight-year UK coastal exposure trials," Magazine of Concrete Research, vol. 51, no. 2, pp. 87-96, 1999.

[19] H. W. Song, C. H. Lee, M. S. Jung, and K. Y. Ann, "Development of chloride binding capacity in cement pastes and influence of the $\mathrm{pH}$ of hydration products," Canadian Journal of Civil Engineering, vol. 35, no. 12, pp. 1427-1434, 2008.

[20] B. Standard, Structural Use of Concrete: Code of Practice for Design And Construction, BS 8110-1, British Standards Institute, London, UK, 1985.

[21] C. L. Page, N. R. Short, and A. El Tarras, "Diffusion of chloride ions in hardened cement pastes," Cement and Concrete Research, vol. 11, no. 3, pp. 395-406, 1981.

[22] D. Pfeifer, J. Landgren, and A. Zoob, Protective Systems for New Prestressed and Substructure Concrete. Final Report, 1987.

[23] K. Y. Ann, H. S. Jung, H. S. Kim, S. S. Kim, and H. Y. Moon, "Effect of calcium nitrite-based corrosion inhibitor in preventing corrosion of embedded steel in concrete," Cement and Concrete Research, vol. 36, no. 3, pp. 530-535, 2006.

[24] K. Y. Ann and H.-W. Song, "Chloride threshold level for corrosion of steel in concrete," Corrosion Science, vol. 49, no. 11, pp. 4113-4133, 2007. 

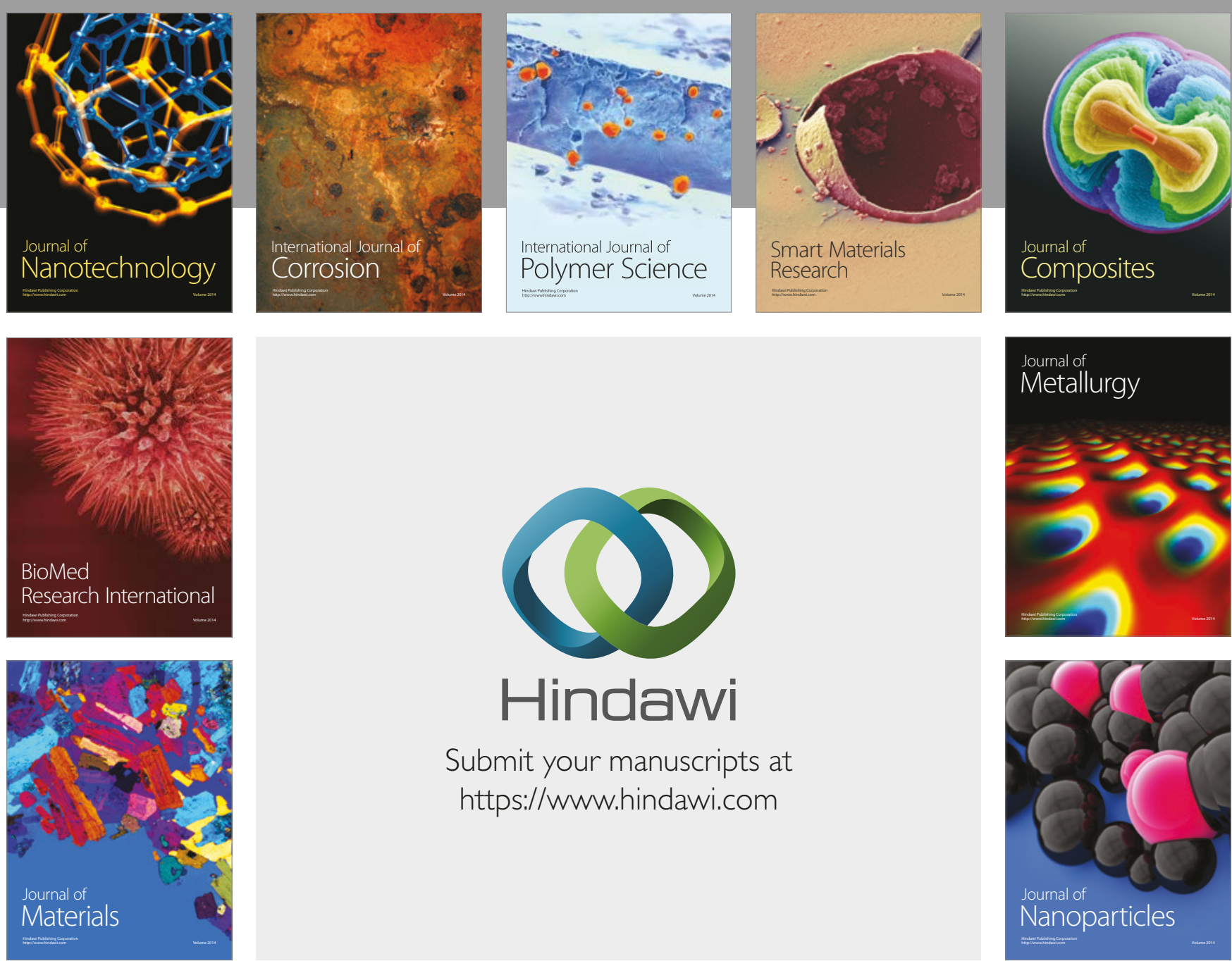

\section{Hindawi}

Submit your manuscripts at

https://www.hindawi.com
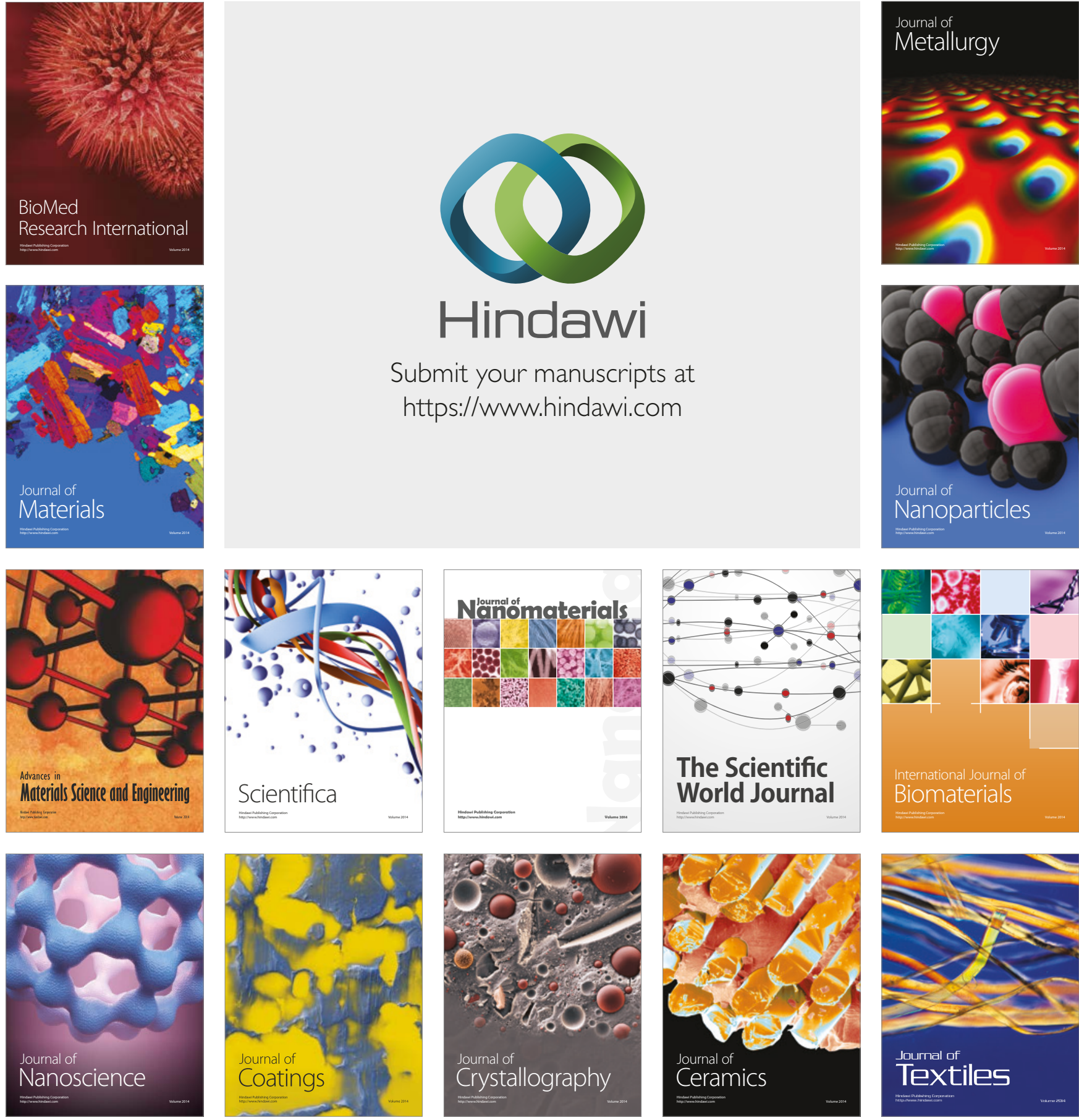

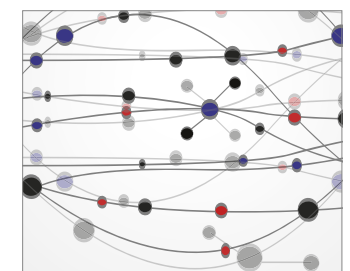

The Scientific World Journal
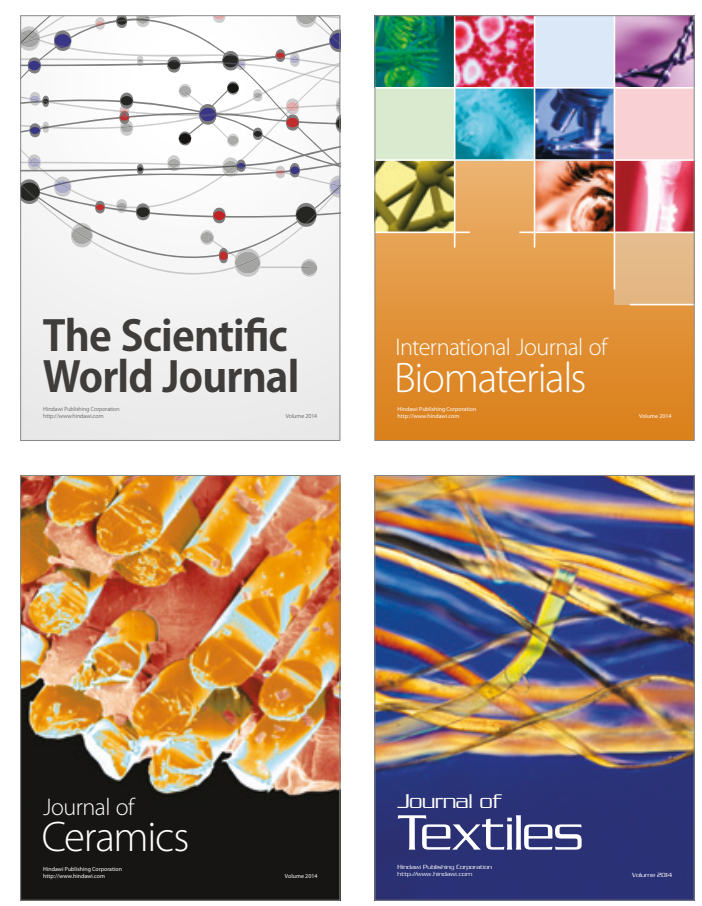